Portland State University

PDXScholar

\title{
Group Counseling for Students Transitioning out of Postsecondary Education
}

Joel A. Lane

Portland State University, lanejoel@pdx.edu

Follow this and additional works at: https://pdxscholar.library.pdx.edu/coun_fac

Part of the Secondary Education and Teaching Commons, and the Student Counseling and Personnel Services Commons

Let us know how access to this document benefits you.

\section{Citation Details}

Lane, Joel A., "Group Counseling for Students Transitioning out of Postsecondary Education" (2013). Counselor Education Faculty Publications and Presentations. 25.

https://pdxscholar.library.pdx.edu/coun_fac/25

This Post-Print is brought to you for free and open access. It has been accepted for inclusion in Counselor Education Faculty Publications and Presentations by an authorized administrator of PDXScholar. Please contact us if we can make this document more accessible: pdxscholar@pdx.edu. 
Group Counseling for Students Transitioning Out of Postsecondary Education: A

\author{
Narrative Approach \\ Joel A. Lane \\ Oakland University \\ Department of Counseling \\ Rochester, Michigan 48309 \\ United States \\ Phone: 248-370-2644 \\ Fax: 248-370-4141 \\ Email: jalane@oakland.edu
}

\begin{abstract}
Summary
This paper proposes a Narrative-based group counseling model for postsecondary students preparing to graduate and transition out of university life. The challenges associated with this transition are both psychological and career-related in nature. The author utilizes multiple transition frameworks to provide a conceptualization of the graduation transition, and offers an overview of narrative therapy, its use in transition counseling, and its use in groupwork. The proposed intervention calls for two facilitators and between six and eight members. An intervention overview is provided that includes recruitment and prescreening instructions as well as content for eight sessions.
\end{abstract}

Keywords: group counseling, narrative therapy, postsecondary graduation, transition, emerging adulthood 
Group Counseling for Students Transitioning Out of Postsecondary Education: A

\section{Narrative Approach}

Graduation from a postsecondary program is commonly regarded as a positive experience in which individuals leave university prepared to embark on their journey into career life and other adult roles. A small but growing number of studies, however, have identified drastically different, less positive, attitudes toward this experience. Mostly qualitative in nature, these studies have identified themes among impending or recent graduates of uncertainty (Perrone \& Vickers, 2003), ambivalence (Yazedjian, Kielaszek, $\&$ Toews, 2010), changes in priorities and personal relationships (Overton-Healy, 2010), fear related to leaving behind support networks and the student lifestyle (Pistilli, Taub, \& Bennett, 2003; Taub, Servaty-Seib, \& Cousins, 2006), anxiety and lack of direction (Allen \& Taylor, 2006), and career disillusionment (Murphy, Blustein, Bohlig, \& Platt, 2010; Polach, 2004).

This research adds complexity to what was previously understood regarding the difficulties of the graduation transition. Prior research has focused almost exclusively on the career implications of this transition (Blustein, Phillips, Jobin-Davis, Finkelberg, \& Roarke, 1997; Gardner, 1998; Holton, 2001; Perrone \& Vickers, 2003; Polach, 2004; Wendlandt \& Rochlen, 2008; Worthington \& Juntunen, 1997). These studies have identified important issues, including high initial job turnover rates (Wendlandt \& Rochlen, 2008), difficulty securing employment (Chickering \& Schlossberg, 1998), and unpreparedness for workplace culture (Hettich, 2010; Wendlandt \& Rochlen, 2008). In considering the aforementioned findings highlighting the psychological implications of the graduation transition, however, it is clear that these career-related issues do not tell 
the entire story. A more holistic understanding of this transition considers career issues in addition to concerns about leaving behind friends, support systems, and the student lifestyle (Pistilli et al., 2003).

In light of these concerns, there is need for interventions designed specifically to address both the psychological and career aspects of preparing to graduate from university. Murphy et al. (2010), in a qualitative study of recent graduates, identified the utility in university counselors targeting students in their final year of postsecondary study with efforts aimed at helping them transition out of university life. Yazedjian et al. (2010), whose qualitative study of postsecondary students in their final year of study yielded themes of ambivalence and ambiguity related to graduating, suggested that individual and group counseling could provide helpful resources for assisting these individuals through the graduation transition. Groupwork in particular, with its emphasis on relational support (Steinberg, 2010; Yalom \& Leszcz, 2005), is positioned as a beneficial approach for this transition, as social support seems to impact subjective wellbeing among recent graduates (Murphy et al., 2010). Both counselors and students would benefit from a group counseling model that considers the graduation transition. The proceeding discussion outlines such a model. This model applies a narrative therapy (White \& Epston, 1990) theoretical framework to develop a group counseling intervention designed to assist graduating university students in externalizing their fears related to graduation, cultivating their preferred post-university identities, and motivating proactivity toward achieving these identities. Prior to this outline, however, a rationale is provided for the use of narrative therapy in the proposed intervention, and consideration is given to conceptualizing the graduation transition. 


\section{Narrative Therapy}

The focus of narrative therapy is on the self-descriptions (i.e., narratives) that individuals knowingly and unknowingly create about their lives, and how these narratives are self-sustaining and influence perceptions (White \& Epston, 1990). Narratives are derived from individual factors, including worldviews and experiences, as well as external factors, including social, familial, and societal influence. As narratives develop and gain power, they influence experience by highlighting events that support them and diminishing those that do not. In effect, social influence, narratives, and experience all impact and are impacted by one another.

Narratives can become problematic when they are restrictive of our perceived capabilities (White \& Epston, 1990). As an example, an individual who has developed a dominant 'depression' narrative will reflect upon past events that support this conclusion while also experiencing new information from the perspective of a depressed individual. The dominant narrative diminishes one's ability to see contradictory evidence and, as a result, becomes self-sustaining and internalized.

Positive change occurs when the evidence supporting alternate narratives gains sufficient power to discredit the relevance of the problematic narrative (White \& Epston, 1990). When this occurs, the problematic narrative becomes externalized (i.e., seen as being separate from the individual) and loses it dominance over the individual. The primary objective in working from a narrative perspective, therefore, is to weaken the power of the problematic narrative while assisting in identifying and developing preferred narratives. The steps involved in this process are to 1) gain awareness of the societal discourses that influenced the creation of the dominant narrative, 2) examine the 
various ways in which the dominant narrative has been problematic and restrictive, and 3) create an external view of the problem as an adversary to be fought against. To quote Epston (1993), "the person is not the problem, the problem is the problem" (p. 161).

\section{The Use of Narrative Therapy in Groupwork}

Though the application of narrative therapy to groupwork is not yet commonly found in counseling literature, there exists a small sample of works demonstrating its efficacy in a diverse range of group applications, including individuals with eating disorders (Weber, Davis, \& McPhie, 2006), survivors of the holocaust (Dasberg, Bartura, \& Amit, 2001), men with anger management deficits (Brcak, 2005), individuals with disabilities (Silvester, 1997), and female victims of male violence (Wood \& Roche, 2001). Dean (1998) asserted that narrative concepts lend themselves naturally to the central process of groupwork: the mutual sharing of stories and receiving of feedback. In receiving feedback, members are exposed to numerous reconstructions of their stories, thereby facilitating the restorying process.

\section{Narrative Therapy and Transition Counseling}

The objectives of narrative therapy offer several parallels to the process of counseling adults in transition set forth by Anderson, Goodman, and Schlossberg (2012). An important component of their contextual approach is to help individuals renegotiate self-definitions in response to life changes. Anderson et al. stress the importance of social and cultural factors in dictating how transitions are experienced. These components mirror the central task of narrative therapy to understand and change the life stories from which individuals derive meaning. 
Theoretically, then, narrative therapy seems to be a natural fit for counseling individuals in transition. Its efficacy in this regard has been demonstrated for the specific transition of aging (Kropf \& Tandy, 1998). Kropf and Tandy (1998) discussed the work of helping older adults to separate their narratives from the dominant narrative of ageist stereotypes and to process transitions such as the death of life partners and the deterioration of health. They described how clients were able to change the themes of their narratives from depression and loss to reflection, accomplishment, and survival. This reconstruction could apply to the transition of university graduation, which also can be experienced as a period of loss (Vickio, 1990).

\section{Conceptualizing the Graduation Transition}

Various transition frameworks offer support for the idea that students in their final year of postsecondary education are at risk for experiencing transition difficulties. Bridges (2003) conceptualized the initial phase in the process of transition as an ending; individuals must leave behind previous ways of being in order to transition into new roles. This phase can be applied to the year prior to graduation, as individuals are presented with the impending finality of the university experience and inevitable changes in life roles. Brammer and Abrego (1981) proposed a model of processing transitions in which the initial stages are often marked by immobilization, denial, and self-doubt. Anderson et al. (2012) stressed that contextual factors impact the subjective transition experience. These models support the evidence that there are considerable individual differences in the subjective experience of the graduation transition (Allen \& Taylor, 2006; Murphy et al., 2010; Overton-Healy, 2010), and that many individuals experience 
considerable distress related to graduating (Allen \& Taylor, 2006; Pistilli et al., 2003; Taub et al., 2006; Vickio, 1990; Yazedjian et al., 2010).

One explanation for the ambivalent and negative feelings about graduation among impending graduates can be found in Arnett's (2000) conceptualization of emerging adulthood. Arnett used this term to describe present-day 18-25 year-olds as a result of recent changes in the normative developmental trajectories of individuals in this age group. As it is no longer normative for individuals to have settled into long-term careers, married, and begun to have children by the time they are 25, Arnett contended that 18-25 year-olds are experiencing unprecedented freedom from typical adult role obligations. The pertinence of this freedom to the concept of transition is twofold: 1) it affords emerging adults the opportunity to engage in extended identity exploration that, according to Arnett, frequently extends past the typical ages associated with graduation; and 2) it results in significant variability regarding the presence (or absence) of life circumstances consistent with adulthood (e.g., living with parents vs. living alone, financial independence vs. financial dependence). Thus, it is likely that emerging adults differ with regard to subjectively feeling ready for life after graduation, with some experiencing graduation as a logical next step in their journey into adulthood, and others believing that leaving behind the university lifestyle will thrust them into adult roles for which they are ill-prepared.

Graduation distress, then, could be understood as the result of feeling that one has not yet settled on crystallized adult identity roles while simultaneously feeling pressured by the societal expectation that these roles be decided upon by the time one graduates. Consistent with the assertions of Anderson et al. (2012), the presence or absence, 
duration, and severity of this distress could vary greatly depending upon contextual factors and life circumstances. The narrative transition framework offered by McAdams and Bowman (2001) provides support for this understanding. They described how negative transition stories are often marked by "contamination sequences" (p. 18) in which individuals perceived positive life progress as being derailed by negative circumstances outside of their control. The stories of those who reflect upon transition positively, however, seem to have reframed these events as "redemption sequences" (p. 6) in which the pain of transition ultimately led to positive life growth. In applying these concepts to the graduation transition, those experiencing distress perceive the expectation that graduates have settled into adult roles as a contamination sequence interfering with the student lifestyles they have grown accustomed to living. An important consideration of the proposed intervention, then, should be to assist members in reconceptualizing the plots of their graduation stories.

\section{Group Design Considerations}

The proceeding discussion considers an effective group format for counseling graduating university students. In developing this group model, I am drawing upon the aforementioned considerations of narrative therapy and transition, as well as personal professional experience utilizing a narrative approach in advising, university counseling, and clinical practice settings, both individually and in groups, with emerging adults transitioning out of postsecondary programs.

\section{Roles of the Facilitators}


The counselor-client relationship in narrative therapy is unique with respect to other treatment modalities (Monk, 1997). According to Silvester (1997), it is necessary for:

... a group leader in a narrative style [to] seek to discover the history, context, and meaning people give to an issue ... and to open space for them to story their own strengths and preferred ways of being (p. 233).

Narrative therapists reject the therapist-as-expert premise in favor of a collaborative role in which the counselor works as a coexplorer with the client (Dean, 1998). The application of this approach to groupwork results in the benefit of multiple coexplorers: the client, each facilitator, and the other members. By sharing stories and relevant feedback, this collective works toward the restorying of each member. Because of the benefit of additional coexplorers, it is recommended that the group utilize two facilitators and be composed of six-to-eight members.

Attaining a coexploration dynamic requires the facilitators to expend effort toward the shaping of group norms from the onset of the group. In these early stages, members frequently are overly rational regarding the problems they discuss (Yalom \& Leszcz, 2005). As cohesion develops, however, members begin to feel comfortable describing the true, irrational nature of their problems. To combat this reluctance, initial efforts should be made toward the cultivation of norms that celebrate openness, honesty, and collaboration. As members begin to believe that the group is a safe place, they will be more open to sharing their stories and offering insightful feedback to other members.

The specific language used by the facilitators is crucial in establishing a story focus (Dean, 1998). From the group's onset, facilitators must cultivate the story-centered 
norm with language such as, 'Let's go around and share the story of how we came to be in this group.' The facilitators can start subsequent sessions with check-in questions such as, 'What new developments in your stories have occurred since the last time we met?' When members share problem-saturated stories, facilitators can intervene with externalizing questions that challenge self-blaming assumptions. The facilitators can model inquiry about specific details contained within each story to establish norms encouraging members to inquire as well. As collective interest in the stories of other members increases, so too will the cohesion and collaborative spirit of the group, resulting in a united group working toward the successful transition out of university life.

\section{Group Goals}

The group model has been developed to assist members in addressing the following goals:

1. Understand and acknowledge the significance of the university experience.

2. Develop universality regarding pre-graduation distress.

3. Understand and prepare for common difficulties associated with transitioning into post-university life.

4. Identify and externalize potential discourses contributing to pre-graduation anxiety.

5. Develop preferred narratives and identify past experiences that are consistent with these narratives.

6. Evaluate preparedness for the next phase of life.

7. Develop strategies for enhancing deficient areas of preparedness.

8. Create stories of success. 


\section{Overview of the Group Intervention}

The proceeding discussion considers content for each session, including goals, instructions, and homework. This overview is intended to offer a framework that is sufficiently detailed to assist facilitators in structuring the group, and yet sufficiently open-ended to accommodate flexibility regarding facilitator preferences and the specific needs of the group members. This flexibility is an integral component of the narrative framework; facilitators should be sensitive to the unique dynamics of each group and make content adjustments where necessary.

\section{Participant Recruitment and Prescreening}

Faculty members and administrators who work closely with students, including advisers, residence hall directors, or career counselors, are ideally positioned to identify individuals who either are experiencing distress due to the graduation transition or stand to benefit from processing the end of the postsecondary experience in a group setting. Therefore, the facilitators should approach individuals holding these positions to inform them of the group and encourage them to use it as a referral source for postsecondary students whom they feel it would benefit. Facilitators should provide contact information and the anticipated starting date for the group.

As facilitators are contacted by prospective group members, prescreening interviews should be scheduled. Prospective group members will meet individually with both co-facilitators for approximately 30-45 minutes. The facilitators should describe the purpose and goals of the group and answer any related questions. The prescreening interview will also allow the facilitators to evaluate each prospective member's readiness to participate in a group. According to Yalom and Leszcz (2005), individuals with rigid 
attitudes or who are overly self-interested tend to be ill-suited for therapy groups.

Individuals who either resist interpersonal intimacy or seek it too quickly also present challenges to group dynamics, but still may benefit from and provide positive contributions to groups. Thus, facilitators should be careful not to include too many members who seem likely to have intimacy problems. Prospective members who are determined to be poor fits for the group should be offered referrals for individual counseling.

\section{Session 1: Introduction, Group Norms, Normalizing Graduation Anxiety}

Content goals. Members will introduce themselves and offer a narrative of their decision to join the group. The group will also discuss and agree upon group rules and norms.

Process goals. Help group members acclimate to and feel safe in the group experience. Begin to normalize and externalize member anxiety.

Instructions. Participants will share their names and talk about their decision to join the group. Facilitators should encourage equal participation among members. Following this activity, the facilitators can begin to develop universality by summarizing member stories and identifying commonalities. Universality is a significant component of group cohesion (Yalom \& Leszcz, 2005). When reflecting member dialog, facilitators should seek opportunities to use externalizing language for member problems (e.g., 'It sounds like the idea that you need to know what to do with the rest of your life has really been trying to keep you from being happy this semester, hasn't it?'). Facilitators should devote 10-15 minutes to psychoeducate members regarding the transition of graduation, letting them know that many graduating students feel ambivalent and uneasy about 
leaving university and beginning the next phase of life, and that, often, they do not realize that their peers are experiencing similar feelings. This information can lead into a discussion about the members' feelings toward graduating. The facilitators should, again, identify common themes and use externalizing language. The final 25-30 minutes of the session should be devoted to discussing and establishing norms, rules, and expectations for the group. The facilitators should write the group rules on a large piece of paper and bring the list to all subsequent sessions.

Homework. Members will be instructed to think of their goals for the group and to come to the next session prepared to discuss those goals.

\section{Session 2: Goal Setting, Getting to Know Our Fears}

Content goals. Members will discuss the homework assignment and attain consensus regarding group goals. Members will participate in a group discussion exploring the nature, context, duration, and impact of their fears about graduation, and facilitators will help them do so using externalizing language.

Process goals. Group members will begin to adopt an externalized view of their problems.

Instructions. The group should begin with a check-in activity in which each member verbally responds to a fill-in-the-blank question: 'my goal for my time in group is because ___ Facilitators should assist members in processing these goals and highlight the common themes. The remainder of the session should be devoted to helping members acknowledge and process their concerns. The conversation could begin with a question ('When you think about your goals and reasons for deciding to join this group, what is keeping you from feeling at peace and leading to your decision to be in 
this group?'), or the group leaders could facilitate its natural development out of the initial conversation related to group goals. Facilitators should respond reflectively and with questions aimed at adding specificity to member descriptions of their problems, and should do so using language that is both externalizing and inquisitive of potential discourse-saturated thinking. Near the end of the conversation, the facilitators may choose to identify this externalizing language and share the rationale for its use. This verbal acknowledgement can serve as a precursor to the homework assignment.

Homework. Members will be asked to choose a name that personifies their problem. No parameters should be placed on the name choosing, only that it will be the name that is used to refer to their problems through the course of the group.

\section{Session 3: Tracking the Problem's History}

Content goals. Members will share their problem identities with one another and participate in an influence mapping interview. The facilitator(s) will offer psychoeducation aimed at Wendlandt and Rochlen's (2008) conception of “addressing anticipation needs" (p. 159).

Process goals. Participants will consider their problems in a historical sense. Doing so will help members achieve a richer understanding of their problems and increase motivation to overcome them.

Instructions. Following a brief check-in activity of the facilitators' choosing, the group should discuss the name that each member gave to their problem and the meaning behind the name (cf. Zimmerman \& Dickerson, 1996). Facilitators should gauge the degree of spontaneous inter-member interaction taking place and continue to encourage this interaction if needed. Such encouragement could come in the form of inviting 
members (specifically or as a whole) to reflect upon what one member has shared, or by techniques such as silence that convey the expectation that members should not wait for cues from the facilitators to respond to one another. During this discussion, facilitators should utilize influence mapping (White, 2007) questions that will aid members in reflecting upon the historical impact of their problems in their lives (e.g., 'How might have been with you at other times in university?' 'What about before university?'

'When is the first time you can remember trying to mess up your life?').

During the psychoeducation portion of the session, facilitators will discuss the views of Wendlandt \& Rochlen (2008) that a major source of difficulty when adjusting to career life after postsecondary education is the discrepancy between anticipated and actual aspects of the career environment. Individuals whose expectations are more accurate report more positive experiences in the early stages of their employment (Kammeyer-Mueller \& Wanberg, 2003). The group should then engage in a discussion regarding the attainment of more accurate expectations. Facilitators should probe the members for their ideas but also be ready with their own suggestions (e.g., interviewing recently employed peers, tempering expectations regarding starting salaries, normalizing common periods of social adjustment).

Homework. Members will develop 2-3 goals for the first year after graduation. Facilitators should encourage members to consider the content of the session while determining goals.

\section{Session 4: Our Goals and Our Problem's Goals}

Content goals. Group members will discuss their immediate post-university goals and how their problems may be seeking to keep them from realizing these goals. 
Members will write themselves a letter helping them identify and become aware of when they are under the influence of their problem.

Process goals. Member narratives of preferred selves will be developed and the separateness of problem narratives will be strengthened. Members will increase selfawareness regarding problem triggers and their impact on member functioning.

Instructions. The facilitators should devote the first 15-20 minutes of the session to a check-in activity in which members are asked to share their goals for the first year after graduation. During the next 30 minutes, the group should engage in a discussion exploring ways in which the members' problems seek to interfere with their goals. Facilitators should ask questions such as 'How do you think will try to interfere with your plans?' and 'Why do you think ___ wants to keep you from achieving these goals?'. For the remainder of the session, the facilitators should initiate an activity in which the members write a letter to their future selves identifying warning signs indicative of their problems seeking to influence them again. Members should be instructed to carefully consider any warning signs, including thoughts, feelings, or behaviors, that would be indicative of their problems seeking to gain power again.

\section{Session 5: Finding Unique Outcomes}

Content goals. Members will reflect upon and discuss instances in which they felt closer to their preferred selves and their behaviors or sentiments were incompatible with their problem identities.

Process goals. The group will seek to make meaning out of these unique outcomes and help one another develop preferred narratives. 
Instructions. Following a brief check-in activity, the facilitators can begin the discussion by inviting members to consider instances in which their problems seemed less powerful. The facilitators should utilize probing questions to make each description as specific as possible. As each member gives several examples, the facilitators will ask the other members to make sense of the unique outcomes. Conversations aimed at organizing unique outcomes are referred to as landscape of action conversations (White, 1992) and help individuals take ownership of the fact that problematic narratives are insufficient self-definitions. The facilitators can then assist the original member to engage in a landscape of consciousness conversation, during which individuals derive meaning from the landscape of action dialog and take ownership of the aspects of their preferred selves that they already possess.

\section{Session 6: Identifying Coping Sources}

Content Goals. Members will discuss and help one another brainstorm their sources of support and how to develop support resources where needed.

Process Goals. Members will identify support resources that can be used in the transition process.

Instructions. The facilitators will open with a brief check-in activity and then lead members through a discussion that helps them identify: 1) current coping resources, including friends, family, organizations with which the members are affiliated; 2) how those resources have been helpful in other situations; 3) how members might rely upon them as they transition out of university; 4) additional coping sources that may aid in the transition process, and 5) how to go about recruiting those coping sources. These 
discussion topics are derived from White's (2007) concept of re-membering conversations.

It is anticipated that members' coping sources will be complementary: some members will have ideas about how to utilize their coping sources that other members will want to incorporate into their coping network, and vice versa. Facilitators, however, should be prepared to offer suggestions if members encounter difficulty in brainstorming ways to continue to use resources. For example, members worried about less frequent communication with close friends could be encouraged to consider the suitability of free internet communication programs in allowing them to rely upon that friend during times in which the transition is more difficult. Those whose concerns pertain to job searching could be encouraged to schedule appointments with university career centers to have resumés evaluated and to receive informational support. Doing so will allow members to take an inventory of available support and to become motivated to develop additional support resources, an integral step in the transition process according to Anderson et al. (2012).

\section{Session 7: What is the Story Now?}

Content Goals. Members will discuss the developing narratives of both their problems and preferred identities, and consider additional steps for continued development.

Process Goals. Members will integrate their problem conceptualizations, preferred selves, coping plans, and understandings about life after graduation to develop a thorough picture of expectations and how to prepare for anticipated challenges. 
Instructions. Facilitators will open the session with a brief check-in activity and then provide members with a 'Tracking the Story' worksheet (see Figure 1). Members will complete the worksheets, and the remainder of the session will be spent allowing each member to share their answers with one another. Each member should share the entirety of their worksheet before moving to a different member, as the worksheet questions create a developing narrative.

Homework. Members will create a visual timeline to bring to the next session that incorporates their answers to questions five and six on the worksheet. The timeline will serve as an action plan for their remaining objectives. Members should be instructed that they are free to decorate the timeline if they wish.

\section{Session 8: Termination}

Content goals. Members will reflect upon their experiences in the group, how they have changed as a result of the group, and how they will continue to utilize what they have learned and complete their remaining objectives.

Process goals. Members will attain closure of the group experience and strategize for continued growth.

Instructions. In the week prior to the final session, the facilitators should prepare certificates for each member that signify their completion of the group, and also write a letter to each member that outlines the facilitators' observations of the member's growth and offers encouragement for continuing to pursue goals (cf. Chen, Noosbond, \& Bruce, 1998). Certificates are often utilized in narrative therapy as they symbolize the group experience (Zimmerman \& Dickerson, 1996), while letters written from therapist to client offer a powerful reinforcing of the developing preferred narrative (White, 1995). 
During the termination session, the facilitators should lead members through a structured discussion in which they can reflect upon memories of the group, voice any potential regrets either generally or with regard to specific members, share what they have learned about themselves and how they feel they have developed, and consider how they can continue this development after the completion of the group. Facilitators should allow time for the members to read and reflect upon their letters, and to present them with their certificates.

\section{Discussion}

Leaving university and entering the next phase of life represents an important developmental challenge for emerging adults, a challenge that often results in a difficult period of transition. This difficulty is compounded by societal narratives that postsecondary graduation is a universally positive experience and that graduates should have a crystallized identity regarding their professional aspirations. Combining group counseling, with its emphasis on interpersonal support, and narrative therapy, which helps individuals become aware of the impact of societal expectations on their distress, offers a powerful means for processing such issues. Clients with whom I have utilized similar interventions to process graduation-related or other types of transitional difficulties have provided feedback that such an approach allowed them to reframe past experiences and anticipate future events with a newfound sense of optimism and direction. These impressions are echoed in empirical accounts of both narrative therapy groups (cf. Silvester, 1997) and also narrative work with populations in transition (cf. Kropf \& Tandy, 1998).

\section{Limitations}


Despite the aforementioned efficacy of narrative therapy in both group formats and also in transition-focused counseling, as well as the need for counseling groups with the proposed population articulated by multiple authors (cf. Murphy et al., 2010; Yazedjian et al., 2010), limitations exist regarding the untested nature of the model. It was designed specifically in response to the aforementioned calls for such models and, thus, has not yet been put into practice in its present form. Clinicians preparing to utilize this group are encouraged to be flexible with its proposed structure in the event of unforeseen complications.

\section{Suggestions for Future Research}

Clearly, the testing and evaluation of this model represents a direction for further research. Other efforts could also focus on the potential for generalizing this model to other types of transitions. With minor modification, it is likely that this model could be useful for individuals who have already graduated and are struggling with the transition process. Future studies could also evaluate the degree to which similar approaches might be effective with other types of transition, or with transition in general.

\section{Conclusion}

This paper has proposed a therapeutic framework to address the transition concerns of graduating postsecondary students. In this framework, the process of helping individuals make meaning of their transition from one life phase to the next is strengthened through collaborative relationships with others in similar situations. In

promoting collaboration and minimizing the reliance on facilitator expertise, members can be further empowered to re-author their transition stories. This approach allows for 
affirming the significance of the postsecondary experience while concurrently inspiring members to prepare for post-university life. 


\section{References}

Allen, J. K. and Taylor, K. (2006) The senior year transition: Women undergraduates search for a path. Journal of College Student Development, 47, 6, 595-608

Anderson, M. L., Goodman, J. and Schlossberg, N. K. (2012) Counseling Adults in Transition: Linking Schlossberg's theory with practice in a diverse world. $\left(4^{\text {th }}\right.$ ed.). New York: Springer

Arnett, J. J. (2000). Emerging adulthood: A theory of development from the late teens through the twenties. American Psychologist, 55, 5, 469-480

Blustein, D. L., Phillips, S. D., Jobin-Davis, K., Finkelberg, S. L. and Roarke, A. E. (1997). A theory-building investigation of the school-to-work transition. The Counseling Psychologist, 25, 3, 364-402

Brammer, L. M. and Abrego, P. J. (1981) Intervention strategies for coping with transition. The Counseling Psychologist, 6, 1, 2-9

Brcak, J. A. (2005) Anger Management for Men: A group approach based on narrative therapy and masculine gender socialization. (Doctoral dissertation, Alliant International University). Retrieved from http://gateway.proquest.com/openurl\%3furl_ver=Z39.882004\%26res_dat=xri:pqdiss\%26rft_val_fmt=info:ofi/fmt:kev:mtx:dissertation\%2 $\underline{6 r f t \_d a t=x r i: p q d i s s: 3191966}$

Bridges, W. (2003) Managing Transitions: Making the most of change ( $2^{\text {nd }}$ ed.). Cambridge, MA: Perseus 
Chen, M.-W., Noosbond, J. P. and Bruce, M. A. (1998) Therapeutic document in group counseling: An active change agent. Journal of Counseling \& Development, 76, 4, $404-411$

Chickering, A. W. and Schlossberg, N. K. (1998) Moving on: Seniors as people in transition. In J. N. Gardner, G. Van der Veer, and Associates The Senior Year Experience: Facilitating integration, reflection, closure, and transition. San Francisco: Jossey-Bass

Dasberg, H., Bartura, J. and Amit, Y. (2001) Narrative group therapy with aging child survivors of the holocaust. The Israeli Journal of Psychiatry and Related Sciences, 38, 27-35

Dean, R. G. (1998) A narrative approach to groups. Clinical Social Work Journal, 26, 2337

Epston, D. (1993) Internalizing discourses versus externalizing discourses. In S. G. Gilligan and R. Price Therapeutic conversations. New York: Norton

Gardner, J. N. (1998) Are college seniors prepared to work? In J. N. Gardner, G. Van der Veer, and Associates The Senior Year Experience: Facilitating integration, reflection, closure, and transition. San Francisco: Jossey-Bass

Hettich, P. I. (2010) College-to-workplace transitions: Becoming a freshman again. In T. W. Miller Handbook of Stressful Transitions Across the Lifespan. New York: Springer

Holton, E. F. (2001) New employee development tactics: Perceived availability, helpfulness, and relationship with job attitudes. Journal of Business and Psychology, 16, 73-85 
Kammeyer-Mueller, J. D. and Wanberg, C. R. (2003) Unwrapping the organizational entry process: Disentangling multiple antecedents and their pathways to adjustment. Journal of Applied Psychology, 88, 5, 779-794

Kropf, N. P. and Tandy, C. (1998) Narrative therapy with older clients: The use of a “Meaning-Making” approach. Clinical Gerontologist, 18, 4, 3-16

McAdams, D. P. and Bowman, P. J. (2001) Narrating life's turning points: Redemption and contamination. In D. P. McAdams, R. Josselson and A. Lieblich Turns in the Road: Narrative studies of lives in transition. Washington, DC: American Psychological Association

Monk, G. (1997) How narrative therapy works. In G. Monk, J. Winslade, K. Crocket and D. Epston Narrative Therapy in Practice: The archaeology of hope. San Francisco: Jossey-Bass

Murphy, K. A., Blustein, D. L., Bohlig, A. J. and Platt, M. G. (2010) The college-tocareer transition: An exploration of emerging adulthood. Journal of Counseling and Development, 88, 2, 174-181

Overton-Healy, J. (2010) First-Generation College Seniors: A phenomenological exploration of the transitional experience of the final college year. (Doctoral dissertation, Indiana University of Pennsylvania). Retrieved from dspace.iup.edu/bitstream/handle/2069/249/Julia Overton-Healy.pdf?sequence=1

Perrone, L. and Vickers, M. H. (2003) Life after graduation as a "very uncomfortable world": An Australian case study. Education and Training, 45, 2, 69-78 
Pistilli, M. D., Taub, D. J. and Bennett, D. E. (2003). Development of the senior concerns survey: An exploratory factor analysis. Journal of the First-Year Experience, 15, $39-52$

Polach, J. L. (2004) Understanding the experience of college graduates during their first year of employment. Human Resource Development Quarterly, 15, 5-23

Silvester, G. (1997) Appreciating indigenous knowledge in groups. In G. Monk, J. Winslade, K. Crocket and D. Epston Narrative Therapy in Practice: The archaeology of hope. San Francisco: Jossey-Bass

Steinberg, D. M. (2010) Mutual aid: A contribution to best practice social work. Social Work with Groups, 33, 1, 53-68

Taub, D. J., Servaty-Seib, H. L. and Cousins, C. (2006) On the brink of transition: The concerns of college seniors. Journal of the First-Year Experience and Students in Transition, 18, 2, 111-132

Vickio, C. J. (1990) The goodbye brochure: Helping students to cope with transition and loss. Journal of Counseling and Development, 68, 5, 575-577

Weber, M., Davis, K. and McPhie, L. (2006) Narrative therapy, eating disorders and groups: Enhancing outcomes in rural NSW. Australian Social Work, 59, 4, 391405

Wendlandt, N. M. and Rochlen, A. B. (2008) Addressing the college-to-work transition: Implications for university career counselors. Journal of Career Development, 35, $2,151-165$

White, M. (1992). Deconstruction \& therapy. In D. Epston and M. White Experience, Contradiction, Narrative, \& Imagination. Adelaide, Australia: Dulwich Centre 
White, M. (1995) Re-Authoring Lives: Interviews and essays. Adelaide, Australia: Dulwich Centre

White, M. (2007) Maps of Narrative Practice. New York: Norton

White, M. and Epston, D. (1990) Narrative Means to Therapeutic Ends. New York: Norton

Wood, G. G. and Roche, S. E. (2001) Representing selves, reconstructing lives: Feminist group work with women survivors of male violence. Social Work with Groups, $23,4,5-23$

Worthington, R. L. and Juntunen, C. L. (1997) The vocational development of noncollege-bound youth: Counseling psychology and the school-to-work transition movement. The Counseling Psychologist, 25, 3, 323-363

Yalom, I. D. and Leszcz, M. (2005) The Theory and Practice of Group Psychotherapy ( $5^{\text {th }}$ ed.). New York: Basic Books

Yazedjian, A., Kielaszek, B. J. and Toews, M. L. (2010) Students' perceptions regarding their impending transition out of college. Journal of the First-Year Experience \& Students in Transition, 22, 2, 33-48

Zimmerman, J. L. and Dickerson, V. C. (1996) If Problems Talked: Narrative therapy in action. New York: Guilford Press 
Figure 1. Worksheet for Use During Session 7.

\section{Tracking the Story}

1. This is the story of my fight against At its worst point, my struggle with looked like:

2. Some of the things I used to believe about myself as a result of were:

3. But then I remembered that there was more to the story. Some examples of times in my life that I have been stronger than are:

4. Some resources and/or people I can rely upon in my fight against are:

5. Some specific ways in which I can rely upon these resources/people are:

6. When I think about my fight against , these are some actions I would still like to take that will help me win: 